\title{
DO LIBERALISMO AO NEOLIBERALISMO: LIBERDADE, INDIVÍDUO E IGUALDADE
}

\author{
Adriane Guimarães de Siqueira Lemos \\ Secretaria de Estado da Educação de Goiás (SEDUCGO), Goiânia, Goiás, \\ Brasil
}

\begin{abstract}
RESUMO: O objetivo do texto é compreender a racionalidade que organiza e direciona o movimento do liberalismo ao neoliberalismo na dinâmica de permanências e rupturas. A análise se deu com base em algumas categorias que se enquadram nos fundamentos do liberalismo e neoliberalismo: a liberdade, o indivíduo e a igualdade. A partir disso, percebeu-se que há um retorno dos neoliberais às posições do liberalismo clássico, mas não de forma equivalente. No neoliberalismo há o acirramento e a radicalização das proposições liberais.
\end{abstract}

Palavras-chave: Neoliberalismo. Liberalismo. Liberdade. Igualdade.

\section{INTRODUÇÃO}

O neoliberalismo não rompe completamente com o liberalismo. Do mesmo modo que liberalismo e neoliberalismo também não são idênticos. A relação liberalismoneoliberalismo situa-se na dinâmica de permanências e rupturas. Logo, no movimento histórico do liberalismo ao neoliberalismo, na perspectiva de trajetória do próprio capitalismo, encontra-se uma rica possibilidade de avançar na análise crítica do atual contexto neoliberal. Trata-se de um amplo e complexo movimento, cuja totalidade de manifestações impõe desafios e limites à pesquisa.

Por isso, o objetivo aqui é a análise com base em algumas categorias: a liberdade, conceito que está na origem e na fundamentação da perspectiva liberal/neoliberal; o indivíduo, personagem histórico que se manifesta especialmente com o advento do modo de produção capitalista; a igualdade, princípio indispensável para a organização social capitalista. A partir desses elementos é que se propõe aqui perceber permanências e rupturas no percurso histórico do liberalismo ao neoliberalismo.

\section{FUNDAMENTOS DO LIBERALISMO: LIBERDADE, INDIVÍDUO E IGUALDADE}

Fruto de seu tempo, o liberalismo tem sua origem em um momento histórico em que a estrutura social passa por transformações profundas, o que demanda a explicação da natureza da nova sociedade, bem como a determinação do curso pelo qual poderia se encaminhar. O liberalismo surge como uma resposta. Não a única resposta', todavia foi a mais triunfante, influenciando e justificando o avanço do capitalismo (HOBSBAWM, 1996). 
Desenvolvendo-se e reorganizando-se conforme desdobramentos do próprio modo de produção, as ideias liberais estendem-se de forma desigual e combinada, modificando-se em função das demandas da classe social que detém os meios de produção. Nessas variações da teoria liberal, há princípios basilares que permanecem e que constituem a própria natureza desse corpo de ideias. Ao mesmo tempo, existem diferenças e mudanças dentro do próprio movimento liberal que também manifestam certo grau de continuidade por dizerem da racionalidade que sustenta o liberalismo.

Certamente a liberdade é um pilar fundamental na composição e no desenvolvimento do pensamento liberal. Segundo Merquior (1991, p. 17), o liberalismo nasce na conjuntura de abusos do poder estatal, de intolerância religiosa, de luta por direitos civis, buscando assim "instituir tanto uma limitação da autoridade quanto uma divisão da autoridade" (MERQUIOR, 1991, p. 17), garantindo as liberdades individuais. A liberdade é, dessa forma, a premissa dos primeiros liberais e um importante fundamento para os desdobramentos do movimento liberal.

$\mathrm{Na}$ trajetória em direção ao conceito de liberdade, diferentes realidades e momentos históricos conferiram aspectos próprios ao significado. Para a escola inglesa, a compreensão de liberdade como ausência de coerção, liberdade negativa, predominou em seus principais pensadores. Para os franceses, liberdade vinculou-se especialmente à autodeterminação. Já para os pensadores alemães, a ideia é a possibilidade de realização pessoal, enfatizando assim a liberdade positiva. Dessa forma, liberdade pode ser apreendida como autodesenvolvimento; intitulamento; liberdade política; liberdade de opinião; autogoverno; autonomia; privacidade e independência, entre outros desenvolvimentos do conceito (MERQUIOR, 1991).

Merquior (1991) sinaliza alguns desses desenvolvimentos ao longo da história: primeiro, a luta por liberdade da opressão, em uma busca por dignidade por meio de direitos estabelecidos que garantissem "papéis sociais protegidos pela lei e pelo costume". Merquior (1991, p. 22) a denomina de "liberdade como intitulamento". Depois, a liberdade política, com direito de participação na administração do que se refere à coletividade. Há, também, a liberdade de consciência e crença, evidenciada especialmente pelo pluralismo religioso e pela liberdade de expressão, de imprensa, entre outras. E, por último, a liberdade de realização pessoal, que consiste na "materialização da aspiração de que temos de viver como nos apraz" (MERQUIOR, 1991, p. 23), que se relaciona sobretudo com a "expansão da sociedade de consumo e do tempo dedicado ao lazer" (MERQUIOR, 1991, p. 24).

Por ser um liberal convicto, escapa ao Merquior (1991) as contradições desses desdobramentos da busca pela liberdade ao longo da história. Tais contradições são essenciais para a compreensão dos retrocessos e de dinâmicas que, fundamentadas na liberdade, oneram a população em seus direitos essenciais.

Sem negar os avanços no campo da liberdade para a vida humana, mas fugindo de uma visão romanceada da contribuição dos liberais, faz-se necessário destacar que liberdade e propriedade se imbricam no ideário liberal. Laski (1973, p. 11) evidencia essa contradição ao destacar que "a liberdade que procurou não tinha foros de universalidade, visto que a sua prática estava limitada aos homens que tinham propriedade a defender". 
Além disso, a luta por liberdade política, apenas para exemplificar, advém muito mais dos movimentos sociais do que especificamente do movimento liberal².

Assim, a defesa é sobretudo a liberdade para possuir bens, sem qualquer intervenção. A compreensão de liberdade atravessada pela propriedade sustenta a ideia da "mão invisível" do mercado, isto é, a sociedade regulada pela livre iniciativa privada. A contradição nessa concepção de liberdade está em seu alcance restritivo:

\begin{abstract}
O indivíduo que o liberalismo desejou proteger dispõe sempre de liberdade, por assim dizer, para comprar a sua liberdade na sociedade que construiu; mas o número de indivíduos, com meios de compra à sua disposição, sempre foi uma minoria da humanidade. Em resumo, a ideia de liberalismo está historicamente vinculada, de um modo inevitável, à de posse de propriedade. Os fins a que ele serve são sempre os fins daqueles homens que estão nessa posição. Fora desse estreito círculo, o indivíduo - por quem o liberalismo se mostrava tão zeloso - nunca passou de uma abstração, a quem os seus benefícios jamais puderam, de fato, ser conferidos (LASKI, 1973, p. 13-14).
\end{abstract}

$O$ empenho em proteger a liberdade de propriedade engendra muitas contradições no movimento liberal, como o ataque à democracia, a desconfiança em relação à formação política da sociedade, o esforço para evitar a "politização" da questão econômica e a investida contra políticas sociais (MORAES, 2001).

Junto a isso, o pensamento liberal também se estrutura alicerçado no indivíduo. Entender o que isso significa somente é possível a partir da compreensão do indivíduo em sua natureza histórico-social. Marx (1978, p. 104) explica essa constituição: "quanto mais se recua na História, mais dependente aparece o indivíduo" do seu grupo social, porque o homem é "animal social". O indivíduo isolado é uma invenção moderna, é um produto histórico de uma realidade que aprofunda e generaliza na consciência dos homens a ideia do ser humano singular, único, dono de sua própria vida, de seus sentimentos, dos seus atos e da sua história. Nesse sentido, "só no século XVIII, na 'sociedade burguesa', as diversas formas do conjunto social passaram a apresentar-se ao indivíduo como simples meio de realizar seus fins privados, como necessidade exterior" (MARX, 1978, p. 104).

É nessa lógica, do indivíduo e de seus interesses privados, que o liberalismo organiza as teorias e as ações no plano político-econômico-social. Vale lembrar que a origem do liberalismo liga-se à libertação do indivíduo dos laços da tradição e da lógica coletivista de organização social da Idade Média (LASKI, 1973). Por isso, "parece seguir-se a fórmula de que liberdade é igual a modernidade que é igual a individualismo" (MERQUIOR, 1991, p. 36). O liberalismo surge na e para uma sociedade cada vez mais individualista.

O individualismo no liberalismo apresentou-se sob diferentes facetas que, ainda assim, expressam a unicidade de compreensão do indivíduo acima de tudo. Do legado iluminista de crença na perfectibilidade do homem, passando por uma tendência mais romântica de individualidade espontânea em Stuart Mill ou mesmo pelo individualismo revestido "de uma máscara de cálculo (Bentham)" (MERQUIOR, 1991, p. 62), predominando, dessa maneira, a defesa pelos interesses do indivíduo. 
Na tradição liberal clássica, a ideia é limitar o governo e libertar o indivíduo para agir da forma que lhe apraz, pois "tudo o que não for proibido pela lei é permitido; dessa forma o ônus da justificação cabe à intervenção estatal e não a ação do individual" (MERQUIOR, 1991, p. 17). A liberdade individual ilimitada parece ser entendida como a felicidade não somente particular, do indivíduo, mas também da sociedade. "Argumentavam que a própria busca de interesse pessoal levava à prosperidade geral e, em última instância, à harmonia social. [...] os interesses passaram à frente como um novo paradigma ético" (MERQUIOR, 1991, p. 55).

Os próprios liberais perceberam os problemas inerentes ao aprofundamento do individualismo. Tocqueville via nesse movimento características de uma patologia social, marca de uma sociedade também doente pelo seu apego aos bens materiais e à lógica de competição e animosidade (MERQUIOR, 1991).

A crença na livre atividade do indivíduo buscando seu próprio interesse, na sociedade organizada com base nas individualidades, produz no liberal uma "atitude negativa em relação à ação social", à tradição e qualquer outra orientação filosófica ou política que sobreponha alguma autoridade ou uniformidade sobre a livre iniciativa do indivíduo (LASKI, 1973, p. 12). É evidente que questões relacionadas à universalidade da vida humana se esvaem nesse processo.

O contrato social é anunciado como o marco regulatório da vida em sociedade. O consentimento, via contrato, é que legitima relações individuais e coletivas, validando autoridade e expressando a vontade individual. Para os liberais, o contrato atende preocupações centrais: proteger a propriedade e delimitar o poder, seja do Estado seja dos indivíduos livres que queiram subverter a ordem social. A função do Estado é limitada: manutenção da segurança, serviços essenciais e principalmente "defender os interesses da propriedade" (LASKI, 1973, p. 12). A respeito da função do contrato para o liberalismo, Laski $(1973$, p. 13) ainda observa que:

Nunca compreendeu ou nunca foi capaz de reconhecer completamente que a liberdade de contrato jamais é genuinamente livre, enquanto as partes contratantes não dispuserem de igual poder de negociação e barganha. E isto é, necessariamente, uma função da igualdade de condições materiais.

Na realidade, a igualdade de condições é incompatível com o ideário liberal. Há a defesa da igualdade no liberalismo, mas limita-se à questão jurídica e aos direitos. Isso porque "liberdade e igualdade são valores antitéticos, no sentido de que não se pode realizar plenamente um sem limitar fortemente o outro" (BOBBIO, 1997, p. 39). A igualdade é muito improvável em uma sociedade liberal, "assim como uma sociedade igualitária é inevitavelmente não-liberal" (BOBBIO, 1997, p. 39). A questão é a incompatibilidade de seus fundamentos:

Libertarismo e igualitarismo fundam suas raízes em concepções de homem e da sociedade profundamente diversas: individualista, conflitualista e pluralista a liberal; totalizante, harmônica e monista a igualitária. Para o liberal, o fim principal é a expansão da personalida 
de individual, [...] para o igualitário, o fim principal é o desenvolvimento da comunidade em seu conjunto (BOBBIO, 1997).

A igualdade possível na doutrina liberal é ordenada a partir da propriedade. Trata-se de uma igualdade formal, perante a lei. Isso significa que todos têm liberdade para adquirir propriedade e para viver a vida da forma que melhor the apraz debaixo das mesmas leis, sem "discriminação precedente" (BOBBIO, 1997, p. 40). Reporta-se, assim, à igualdade jurídica, garantida formalmente.

Bobbio (1997, p. 41) ainda elenca outra modalidade de igualdade defendida por liberais: a igualdade dos direitos. Isso "significa o igual gozo por parte dos cidadãos de alguns direitos fundamentais constitucionalmente garantidos", independente da classe social, da religião, do sexo, da raça, da formação etc. A grande questão e que gera muitas controvérsias é: quais são esses direitos fundamentais? Bobbio (1997, p. 41) explica que esses direitos variam "de época para época, de povo para povo, e por isso não se pode fixar um elenco de uma vez por todas".

Dessa compreensão de igualdade advém o embate do liberalismo com a democracia. A democracia liberal também se realiza no plano formal, cujo significado parte de um ordenamento jurídico-institucional de distribuição do poder político. Tratase mais de um procedimento e se distancia, assim, da compreensão de democracia substancial, de significado ético, que busca a igualdade e o governo para o povo (BOBBIO, 1997). Na democracia liberal, "a política não é um dever - é um ofício, uma função confiada por muitos a uns poucos governantes" (MERQUIOR, 1991, p. 84).

Ao longo da história, o ideário liberal foi se modificando, resultando em diferentes vertentes e variadas concepções. Contudo, permaneceu atravessado pela defesa da propriedade e alicerçado em um mundo humano "constituído de átomos individuais com certas paixões e necessidades, cada um procurando acima de tudo aumentar ao máximo suas satisfações e diminuir seus desprazeres" (HOBSBAWM, 1996, p. 256).

Isso não significa dizer que as ideias liberais não trouxeram conquistas importantes para a sociedade. A liberdade religiosa, a organização legal, a luta contra o Estado opressor e tirânico e alguma mobilidade social são conquistas históricas atreladas ao movimento liberal. Além disso, "as relações produtivas que tornou possíveis melhoraram imensamente o padrão geral de condições materiais. O progresso da ciência só foi possível através do clima mental que o liberalismo criou" (LASKI, 1973, p. 14).

Apesar disso, o ideário liberal favoreceu especialmente a burguesia, classe que está na origem e nos desenvolvimentos dessa forma de pensamento; oportunizou o controle do Estado; amparou a constituição do arcabouço jurídico de proteção da propriedade e de validação do poder; justificou as desigualdades mediante o discurso do indivíduo e sua responsabilidade por sua própria liberdade; estabeleceu o contrato que legitima condições desiguais e validou toda uma organização social baseada no acúmulo desenfreado do dinheiro.

Netto e Braz (2012), buscando compreender fenômenos e processos do capitalismo, apresentam um quadro dos estágios de desenvolvimento desse modo de produção. Esses movimentos revelam as contradições de um sistema produtivo que sempre está em crise, pois "não existiu, não existe e não existirá capitalismo sem crise" (NETTO; BRAZ, 2012, p. 170). Isso acontece em razão da natureza do sistema, cuja lógica é 
do valor que precisa valorizar-se ainda mais, o que leva a ciclos econômicos compostos pelas fases: "a crise, a depressão, a retomada e o auge" (NETTO; BRAZ, 2012, p. 172).

À vista disso, é possível depreender o esgotamento do liberalismo? No sentido dos ciclos e das dinâmicas do capitalismo é possível sim. Há esgotamento de determinada resposta do liberalismo no determinado ciclo em que a resposta se manifesta. O keynesianismo ${ }^{3}$, por exemplo, que emerge após a crise de 1929, demonstra os sinais mais agudos de esgotamento em meados dos anos 70 , abrindo a porta para as teorias e ações das políticas neoliberais (NETTO; BRAZ, 2012). Ao mesmo tempo, também é possível perceber a recomposição do liberalismo em função das demandas do próprio capitalismo. A compreensão que perpassa aqui é que a resposta neoliberal deve ser entendida nessa trajetória de esgotamento-recomposição. Nesse sentido, corroboramos a tese de que

o neoliberalismo teorizado por Hayek não significa o fim do novo liberalismo/social-liberalismo de Keynes e Dewey ou mesmo uma negação de todos os fundamentos do liberalismo clássico, e sim uma nova, grande e complexa rearticulação do liberalismo, imposta pela nova ordem econômica e política mundial (LIBÂNEO; OLIVEIRA; TOSCHI, 2003, p. 86).

A burguesia, representada agora especialmente por uma elite econômica, permanece em sua posição de classe dominante. Nesse movimento, fez-se necessária a recomposição do capitalismo e da doutrina político-filosófica que o fundamenta.

\section{A FUNDAMENTAÇÃO NEOLIBERAL: LIBERADADE E O INDIVÍDUO}

Ao olhar para os fundamentos que organizam o construto teórico dos neoliberais, tanto Libâneo, Oliveira e Toschi (2003) quanto Bobbio (1997) entendem como um certo retorno às teses do liberalismo clássico, especialmente no que diz respeito à liberdade. Ainda assim, é possível depreender maior radicalidade no lugar ocupado pelo liberismo ${ }^{4}$ e um caráter restritivo no que se refere a questões ético-políticas.

A concepção de liberdade neoliberal advém da discussão entre filósofos e economistas sobre a relação liberalismo-liberismo. Como emblema desse debate, Benedetto Croce e Luigi Einaudi, na Itália, deliberaram a respeito da questão da identificação liberalismo-liberismo. Para Croce, liberdade é um ideal moral e vincula-se à elevação e virtude individual. Enquanto para Einaudi, economista liberal, "liberalismo ético-político e liberalismo econômico (ou liberismo) são indissolúveis, e onde não há o segundo não pode haver o primeiro" (BOBBIO, 1997, p. 87).

É alicerçado nesse embate que Friedman irá desenvolver a tese da indivisibilidade da liberdade. Não se trata de uma simples identificação entre liberdade econômica e liberdade político-social. Para os neoliberais, a liberdade civil, política, de opinião, religiosa entre outras advém da liberdade econômica (MERQUIOR, 1991). Sem liberdade econômica, não há possibilidade da plena existência da liberdade do indivíduo. É uma condição para a liberdade individual. Em seu fundamento, portanto, o neoliberalismo é uma doutrina econômica para a qual a liberdade econômica é condição sine qua non para as outras liberdades. "O pressuposto de que as liberdades individuais 
são garantidas pela liberdade de mercado e comércio é um elemento vital do pensamento neoliberal" (HARVEY, 2014, p. 17).

Por liberdade econômica se entende a economia de mercado que se autorregula. Para os neoliberais, a economia foi se modificando ao longo da história e evoluindo para a atual forma de organização capitalista. Trata-se de uma visão progressista da história humana, em que se compreende mercado e progresso como parte de uma "moldura evolucionista" (MERQUIOR, 1991, p. 190).

A partir disso, entende-se a organização social totalmente livre para a iniciativa privada, para a concorrência, para a competitividade, para a propriedade e o enriquecimento. $\mathrm{O}$ mercado informa aos agentes econômicos e o progresso advém de um processo de seleção de experiências bem-sucedidas (MERQUIOR, 1991). Assim, quanto maior a liberdade para a concorrência, maior a seleção de boas práticas, o que resulta em eficiência e qualidade não somente de serviços e produtos, mas também nas melhores aptidões, habilidades, mentes e capacidades, propiciando uma evolução social. O que organiza a vida social é, desse modo, a concorrência.

A compreensão de liberdade econômica enquanto condição sine qua non para as outras liberdades produz desdobramentos e proposições contraditórias com o próprio liberalismo. Em função da garantia e preservação dessa liberdade econômica, os neoliberais não medem esforços para remover qualquer obstáculo, até mesmo a democracia. Caso o movimento do povo indique cerceamento à esfera econômica, essa liberdade política da maioria deve ser limitada (BOBBIO, 1997). Por isso não há, para os neoliberais, nenhuma contradição entre regimes autoritários e o receituário neoliberal. Anderson (1995) elucida essa questão ao olhar para as experiências chilena, mexicana, argentina e peruana no final da década de 1980 e na década de 1990.

Derivada dessa perspectiva é que procede a relação neoliberal com o Estado. A defesa do Estado mínimo indicando a ação mais restrita possível visa a garantir a liberdade econômica. Ao mesmo tempo, há "um Estado forte, sim, em sua capacidade de romper o poder dos sindicatos e no controle do dinheiro" (ANDERSON, 1995, p. 11), desonerando especialmente os gastos sociais, criando, assim, as condições para a liberdade econômica. Além disso, fazem parte do receituário neoliberal tendo em vista o livre mercado: a estabilidade monetária; a disciplina orçamentária; a "restauração de taxa 'natural' de desemprego, ou seja, a criação de um exército de reserva de trabalho para quebrar os sindicatos" (ANDERSON, 1995, p. 11); as reformas fiscais; a desestatização; a desregulamentação e privatização, e a proteção e incentivo da iniciativa privada com ênfase na concorrência.

Para David Harvey (2014), o neoliberalismo é mais que uma teoria em que o liberismo é a chave de compreensão para as demais liberdades e para o bem-estar humano. Trata-se de "um projeto político de restabelecimento das condições de acumulação do capital e de restauração do poder das elites econômicas" (HARVEY, 2014, p. 27). Esse pesquisador busca dados do crescimento econômico, de concentração de renda, de inflação, das condições dos trabalhadores, de investimento, de lucros e rendas do capital, entre outros, para revelar que, nos países onde ocorreu a virada neoliberal, houve de fato o aprofundamento das desigualdades sociais ao mesmo tempo que "extraordinárias concentrações de riqueza e de poder" surgiram em toda parte (HARVEY, 2014, p. 26). 
Perry Anderson (1995, p. 16) também percebe o avanço e aprofundamento das desigualdades sociais e o incremento na renda de grupos específicos. Esse autor destaca o aumento da taxa acumulação e focaliza especialmente o movimento especulativo, cujas "operações puramente parasitárias" não geram condições de produção, ou seja, empregos, produtos, serviços etc.

Essas análises, e os dados que as corroboram, revelam que todas as liberdades prometidas pela retórica neoliberal a partir da defesa da liberdade econômica enquanto condição sine qua non aconteceram, principalmente, para uma minoria. "O crescente hiato entre a retórica (em benefício de todos) e a concretização (em benefício de uma diminuta classe dirigente)" é para Harvey (2014, p. 217) exageradamente visível. Apesar disso, a permanência e o avanço neoliberal persistem.

Nesse sentido, Harvey (2014) destaca um elemento importante da retórica neoliberal: o termo liberdade é frequentemente usado na justificativa das ações políticoeconômica-sociais dos governos neoliberais. Harvey verifica que tal discurso desempenha papel indispensável na construção do consentimento e na mobilização da população, acatando e submetendo-se ao receituário neoliberal.

Aliada ao discurso da liberdade, a concepção do indivíduo neoliberal também exerce forte influência na organização social. Merquior (1991, p. 192) destaca na obra de Hayek a preocupação com o indivíduo e sua relação com a liberdade. Se no liberalismo clássico a ideia foi libertar o indivíduo para que aja como lhe apraz, para Hayek há uma excessiva permissividade. Esse contexto afasta o indivíduo do padrão necessário para a efetivação da sociedade civilizada, que caminha para o crescimento e progresso constante. Instintos primários, como a tendência gregária humana, não pactuam com a "sociedade abstrata" que se organiza a partir de normas aprendidas e na livre concorrência. Na sociedade idealizada por Hayek, o indivíduo necessita ser apto para "a fria manipulação de normas que distinguem os membros da sociedade abstrata". Para isso, faz-se necessário o "controle dos instintos, uma boa medida de distância de sentimentos 'tribais', de comunidade e 'comunabilidade'" (MERQUIOR, 1991, p. 193).

Isso não implica controle ou limites para a liberdade do indivíduo. $O$ indivíduo continua pensando e agindo como the apraz. Não se trata de estabelecer valores, objetivos, opiniões, verdades universais ou padrões de conduta e hábitos, mas sim de adaptação à sociedade do livre comércio, do livre mercado, que é altamente competitiva e que caminha ininterruptamente para o progresso. "Quando todas as contas são feitas, a liberdade, para Hayek, é, no fundo, um instrumento de progresso; o mérito supremo do indivíduo 'hayekiano' é contribuir (inconscientemente) para a evolução social" (MERQUIOR, 1991, p. 195). Em outras palavras, o progresso da sociedade advém da liberação das "liberdades e capacidades empreendedoras individuais" (HARVEY, 2014, p. 12).

Assim, não se trata de cercear a liberdade do indivíduo, mas de redefini-la ou reorientá-la em função da racionalidade econômica. Isso porque acredita-se que o neoliberalismo de mercado constitui o avanço natural da humanidade ao longo da história. Tal progresso demanda "mudar o próprio homem", a fim de garantir "uma harmonia entre a maneira como ele vive e pensa e as condicionantes econômicas às quais deve se submeter" (DARDOT; LAVAL, 2016, p. 91). 
Esse processo de adaptação demanda novas qualidades, outra subjetividade, competências específicas e motivações de outra ordem. $O$ indivíduo neoliberal ${ }^{5}$ emerge da própria economia desregulamentada, livre, competitiva e eficiente. É educado nesse contexto para ser o indivíduo econômico, o homem que age, que empreende, que aprende nas condições da concorrência e competitividade.

É o individualismo do homem-empresa. Em uma sociedade em que a liberdade econômica é que gera as demais liberdades, nada mais adequado do que o indivíduo que não somente se envolve com esses livres mercados e livres comércios, ele é mais do que isso. Conforme Dardot e Laval (2016), o indivíduo neoliberal é totalmente formado e constituído na racionalidade do mercado, da concorrência, da produtividade. Ao ponto dele mesmo se fazer empresa, agindo como "uma entidade em competição e que, por isso, deve maximizar seus resultados, expondo-se a riscos e assumindo inteira responsabilidade por eventuais fracassos" (DARDOT; LAVAL, 2016, p. 328).

O individualismo vinculado ao liberalismo diz respeito ao indivíduo que, sozinho na multidão, proprietário da sua vida, história, sentimentos, vontades, busca seus próprios interesses, realizando os seus propósitos privados. Na racionalidade neoliberal, há maior aprofundamento desse individualismo. A lógica do desempenho individual, do indivíduoempresa, exige um individualismo totalmente comprometido com a competitividade. $O$ indivíduo neoliberal precisa ser mais eficaz, mais envolvido no trabalho, mais aperfeiçoado, mais flexível para as mudanças no mercado de trabalho, mais empreendedor, mais competente, com mais desempenho, que se autogoverne e que trabalhe a si mesmo constantemente (DARDOT; LAVAL, 2016).

Esse quadro conforma uma subjetividade cuja realização torna-se o desempenho, por meio de um processo de valorização de si mesmo que não se esgota. A vida passa a ser gerenciada nessa perspectiva: casamento, educação de filhos, amizade, saúde e bem-estar físico, lazer, o uso do tempo, bens, decisões política-religiosa-éticas, entre outros, passam a ser administrados como capital para a autovalorização e como marca do indivíduo bem-sucedido. A "ascese do desempenho" (DARDOT; LAVAL, 2016, p. 339) perpassa todos os âmbitos da vida do indivíduo, em um envolvimento total, levandoo a dispor todas as esferas da vida privada e pública à racionalidade econômica, realizando "a análise de custo-benefício a todo comportamento" (DARDOT; LAVAL, 2016, p. 214).

As consequências dessa racionalidade econômica para a constituição subjetiva e para a vida dos indivíduos ainda precisa ser melhor entendida. Apesar disso, Dardot e Laval destacam algumas questões substanciais. Em uma organização social desregulamentada, na qual o pleno emprego e a segurança do vínculo trabalhista são constantemente atacados, a racionalidade da concorrência e do desempenho "tendem a jogar o peso da complexidade e da competição exclusivamente sobre o indivíduo" (DARDOT; LAVAL, 2016, p. 342).

Na racionalidade da liberdade econômica, enquanto condição sine qua non, há o aprofundamento da individualização em uma intensidade e intimidade com o livre mercado, cujas consequências já podem ser sentidas na descaracterização do humano, no aumento da violência, do suicídio, das doenças psíquicas, entre outros (DARDOT; LAVAL, 2016). A liberdade realmente possível parece ser a da escolha enquanto consumidor. O indivíduo pode comprar o que quiser: produtos, qualificação, "estilos de vida, formas de expressão e uma ampla gama de práticas culturais" (HARVEY, 2014, p. 52). $O$ consumo diferenciado apresenta-se como a marca de individualidade e liberdade. No 
entanto, o engodo permanece, pois o consumo não é possibilidade para todos. Nesse ponto, faz-se necessário compreender a questão da igualdade no neoliberalismo.

Das ações que compõem o receituário neoliberal, o ataque radical às políticas sociais que visam a garantir certo bem-estar e igualdade social seja, talvez, a intervenção mais polêmica e criticada. E também a mais difícil de ser implementada, envolvendo quase sempre estratégias elaboradas de convencimento e muito embate com a população.

Quando Margaret Thatcher assumiu o governo britânico em 1979, além do desmonte dos sindicatos e dos direitos trabalhistas, atuou firmemente para desfazer as políticas sociais, atacando a educação, a saúde e a assistência social. Apesar da ofensiva em algumas áreas, como a educação, Thatcher não conseguiu o apoio da população e pouco avançou no processo de neoliberalização (HARVEY, 2014). As ações de Thatcher exemplificam o receituário neoliberal no que diz respeito às políticas sociais. $O$ fato é que o projeto político-econômico-social neoliberal "opõe-se radicalmente às políticas estatais de universalidade, igualdade e gratuidade dos serviços sociais, como saúde, seguridade social e educação" (LIBÂNEO; OLIVEIRA; TOSCHI, 2003, p. 98). Essas ações relacionam-se diretamente à concepção de igualdade desenvolvida pelo pensamento neoliberal.

Coerentemente com o ideário liberal, os neoliberais também entendem que liberdade e igualdade material são antagônicos no sistema capitalista de produção. Isso porque "o sistema capitalista é produtor de desigualdades sociais" (ABRÃO; MENDONÇA, 2012, p. 50). Ainda assim, não reconhecem a possibilidade de outra forma de organização social mais igualitária. Pelo contrário, Von Mises (ABRÃO; MENDONÇA, 2012) interpretou a desigualdade de renda e riquezas sob uma ótica positiva. Em uma sociedade assentada na racionalidade econômica, a desigualdade é fator decisivo para a responsabilização do indivíduo, impulsionando-o a agir na aquisição de bens e riquezas.

A questão, portanto, é de eficiência e competência individual para sair da condição de miséria. Na economia livre e desregulamentada há, segundo Mises, emprego para todos. Sabendo empregar bem sua propriedade (a força, a capacidade de trabalho), qualquer um pode ter sucesso no mercado consumidor. Nessa mesma perspectiva, Mises justifica a exacerbação da riqueza: no jogo do consumo, obtêm sucesso aqueles mais eficientes e competentes em atender o consumidor. Os bens e riquezas conquistados provêm, assim, da autodeterminação do consumidor. São os consumidores que determinam o consumo e, portanto, a riqueza de alguns (ABRÃO; MENDONÇA, 2012).

Hayek (2010, p. 94) esclarece a distinção e incompatibilidade entre igualdade formal e igualdade substantiva. A função do Estado é garantir a igualdade formal perante a lei. A ação dos governos no sentido de garantir a igualdade substantiva, e aqui entram as políticas sociais, apenas promove "discriminação intencional entre as necessidades particulares de diferentes pessoas, e permite que um indivíduo realize aquilo que outro deve ser impedido de realizar". Para Hayek, a busca de uma justiça distributiva leva, inevitavelmente, ao desmantelamento da igualdade formal.

A desigualdade social é vista como inevitável e necessária. É inevitável porque "o estado de Direito produz desigualdade econômica - tudo que se pode afirmar em seu favor é que essa desigualdade não é criada intencionalmente com o objetivo de atingir este ou aquele indivíduo de modo particular". A desigualdade social é necessária porque 
refere-se às relações organizadas a partir do contrato e não do status social. O governo que tem por objetivo a igualdade substantiva "é obrigado a estabelecer [...] o nível de renda dos indivíduos [...]. Isto significa na realidade um retrocesso à supremacia do status" (HAYEK, 2010, p. 94), dando novamente privilégios.

Assim, a compreensão da igualdade no pensamento neoliberal refere-se ao plano jurídico, em plena concordância com o legado liberal. $O$ direito ganha centralidade nessa perspectiva, pois nele se insere a única igualdade possível:

\begin{abstract}
não faz diferença se todos os automóveis circulam pelo lado direito ou pelo lado esquerdo das ruas, contanto que todos o façam do mesmo lado. $\mathrm{O}$ importante é que a norma nos permita prever com exatidão o comportamento dos outros indivíduos, e isto exige que ela se aplique a todos os casos - mesmo que numa circunstância particular, ela seja considerada injusta (HAYEK, 2010, p. 95).
\end{abstract}

Hayek (2010) ainda explica que é do debate proveniente da compreensão e distinção da igualdade formal e a igualdade substantiva que deriva a confusão existente acerca da questão do privilégio. A propriedade na sociedade da concorrência e regulamentada pelo contrato não é um privilégio. É mérito dos mais eficientes e competentes:

\begin{abstract}
Ela seria efetivamente um privilégio se, por exemplo, como sucedeu por vezes no curso da história, a propriedade da terra fosse reservada aos membros da nobreza. É privilégio também se, como sucede nos nossos tempos, o direito de produzir ou vender determinados bens é reservado pela autoridade a certos indivíduos. Mas chamar de privilégio a propriedade privada como tal, que todos podem adquirir segundo as mesmas normas, só porque alguns conseguem adquirila e outros não - é destituir a palavra privilégio do seu significado (HAYEK, 2010, p. 95).
\end{abstract}

Isso posto, percebe-se que igualdade se vincula ao direito na perspectiva neoliberal. "Hayek é partidário da nomocracia: aquilo de que necessitamos são antes regras do jogo do que valores e objetivos partilhados" (MERQUIOR, 1991, p. 194-195). A desigualdade social é irremediável e, na lógica da concorrência, torna-se fator importante para a eficiência e competência individual. $O$ sucesso e os privilégios de alguns são decorrentes da escolha dos consumidores e atestam a sociedade livre e contratualista. Ao mesmo tempo, políticas sociais e qualquer forma de intervenção visando à igualdade substantiva é conceder privilégios e status para grupos sociais.

Com essa retórica, os neoliberais fecham os olhos para as formas de acumulação de riquezas muito distantes do processo produtivo e negligenciam a histórica expropriação realizada na produção da mercadoria. Também justificam o acúmulo de riqueza responsabilizando o consumidor e ainda levantam a bandeira contra a educação, a saúde, a assistência social, a seguridade social da população trabalhadora por meio do discurso que coloca os direitos fundamentais no âmbito dos privilégios.

\title{
ALGUMAS CONSIDERAÇÕES
}


Partindo de algumas categorias - liberdade, indivíduo, igualdade -, buscou-se ao longo do texto investigar o que aproxima e o que distingue liberalismo e neoliberalismo, nos limites de uma estrutura que não se alterou e permanece, apesar das muitas e inevitáveis crises do capitalismo, como forma predominante de organização societária.

Logo, em função dos processos de recomposição do modo de produção, há também reformulação da interpretação e solução proposta pelos filósofos e economistas do capital. Isso explica a existência de várias correntes liberais e também nuances no movimento neoliberal, bem como as contradições e conflitos entre os intelectuais liberais e neoliberais. Assim, da possibilidade concorrencial, na qual competiam pequenos e médios empresários - contexto de desenvolvimento da teoria liberal clássica -, ao capitalismo dos grandes monopólios e corporações, dos sistemas financeiros e de políticas globais - no qual desponta a resposta neoliberal-, permanecem os interesses de uma classe que obtém especial vantagem e muitos benefícios. Nesse ponto, vale lembrar a tese de David Harvey (2014, p. 27), em que o neoliberalismo é entendido como "um projeto político de restabelecimento das condições de acumulação do capital e de restauração do poder das elites econômicas".

Outra questão substancial no movimento do liberalismo ao neoliberalismo é o acirramento na compreensão das categorias aqui analisadas, com fortes e profundas consequências para a organização social. Assim, a compreensão de liberdade do liberalismo clássico, decorrente do debate entre liberdade negativa e liberdade positiva, estava crivada pela questão da propriedade. Contudo, no neoliberalismo, a liberdade econômica torna-se condição sine qua non para todas as outras liberdades. Por conseguinte, para além do individualismo empreendido no capitalismo liberal, o indivíduo neoliberal é redefinido e reorientado em função da racionalidade econômica.

O acirramento da compreensão e consequentemente da efetivação prática dos conceitos também é percebido na questão da igualdade. Mantendo a tradição liberal clássica, a doutrina neoliberal entende que a igualdade possível em uma sociedade de economia de mercado é a igualdade formal, jurídica, legalmente ordenada. Ainda assim, o neoliberal é mais audacioso. Ele entende a desigualdade social como parte irremediável e necessária no jogo dos negócios, relacionando-a como fomento necessário para a busca por eficiência e competência. $\mathrm{Na}$ sociedade organizada com base no princípio da concorrência e sem privilégios para alguns, terão sucesso aqueles que se venderem melhor, competindo ao consumidor escolher e atestar os melhores.

Portanto, tendo por referência as categorias aqui desenvolvidas, é possível depreender que há um retorno dos neoliberais às posições do liberalismo clássico. Mas não para reiterar tal qual o idealizado pelos filósofos e economistas dos primeiros estágios do capitalismo. No neoliberalismo há o acirramento e a radicalização das proposições liberais em defesas evidentemente mais desagregadoras do tecido social, conservadoras de classe e elitistas. 


\title{
FROM LIBERALISM TO NEOLIBERALISM: FREEDOM, INDIVIDUAL AND EQUALITY
}

\begin{abstract}
The goal of this text is to understand the rationality that organizes and directs the movement from liberalism to neoliberalism in the dynamics of permanences and ruptures. The analysis came from some categories that fit the foundations of liberalism and neoliberalism: the freedom, the individual and the equality. From this it was realized that there is a return of neoliberals to the positions of classical liberalism, but not in an equivalent way. In neoliberalism there is the intensification and radicalization of liberal propositions.
\end{abstract}

KEYWORDS: Neoliberalism. Liberalism. Freedom. Equality.

\section{DEL LIBERALISMO AL NEOLIBERALISMO: LIBERTAD, INDIVIDUAL E IGUALDAD}

RESUMEN: El objetivo del texto es comprender la racionalidad que organiza y dirige el movimiento del liberalismo al neoliberalismo en la dinámica de las permanencias y las rupturas. El análisis se basó en algunas categorías que se ajustan a los fundamentos del liberalismo y el neoliberalismo: la libertad, el individuo y la igualdad. De esto se comprendió que hay un retorno de los neoliberales a las posiciones del liberalismo clásico, pero no de manera equivalente. En el neoliberalismo existe la intensificación y radicalización de las proposiciones liberales.

PALABRAS CLAVE: Neoliberalismo. Liberalismo. Libertad. Igualdad.

\section{NOTAS}

1) Discorrendo sobre a ideologia secular no período entre 1789-1848, Hobsbawm (1996, p. 268) destaca além do liberalismo burguês, o socialismo, a ideologia conservadora e o que o autor denomina "ideologias singularmente equilibradas entre a progressiva e a antiprogressiva", nas quais se destacam o pensamento de Rousseau, Kant e Hegel.

2) A questão do sufrágio universal e a relação dos liberais com a democracia exemplificam essa questão. Para a vertente conservadora do liberalismo, determinadas pessoas que "subsistem mediante a venda de seu trabalho e, portanto, não contando com uma base de propriedade, não são independentes o bastante para o exercício de direitos políticos" (MERQUIOR, 1991, p. 149).

3) Derivado do liberalismo de esquerda desenvolvido por John Maynard Keynes (1883-1946), o keynesianismo consiste em uma compreensão "sobre o papel positivo do Estado: na criação de pleno emprego; na moderação de desequilíbrios sociais excessivos e politicamente perigosos; no socorro a países e áreas economicamente deprimidos; na manutenção de uma estrutura de serviços de bem-estar (habitação, saúde, previdência, transporte urbano, etc.); na gradual implantação de políticas sociais que atenuassem desigualdades materiais acentuadas pelo funcionamento não monitorado do mercado, etc." (MORAES, 2001).

4) Benedetto Croce escreveu um ensaio, em 1928, intitulado Liberalismo e liberismo, no qual destaca que "liberalismo é um princípio ético, o liberismo não passa de um preceito econômico"(MERQUIOR, 1991). Assim, o liberismo refere-se especialmente à liberdade econômica. 
5) Dardot e Laval (DARDOT; LAVAL, 2016) usam o termo sujeito neoliberal para tipificar o individualismo proposto pela lógica neoliberal. Aqui, neste texto, preferimos usar indivíduo neoliberal por se tratar de uma leitura crivada pela relação indivíduo-sociedade já anunciada em Marx (1978).

\section{REFERÊNCIAS}

ABRÃO, L. R. E. S.; MENDONÇA, M. R. Liberdade, igualdade e propriedade: uma amostra do pensamento liberal clássico em FrédéricBastiat, Ludwig Von Mises e Friedrich August Von Hayek. Espaço em Revista, p. 43-54, 2012. Disponível em: https://www.revistas.ufg.br/espaco/article/view/19407. Acesso em: 03 out. 2019.

ANDERSON, P. Balanço do neoliberalismo. In: SADER, E.; GENTILI, P. (Org.). PósNeoliberalismo: as políticas sociais e o Estado democrático. 4. ed. Rio de Janeiro: Paz e Terra, 1995. p. 9-23.

BOBBIO, N. Liberalismo e Democracia. 6. ed. São Paulo: Editora Brasiliense, 1997.

DARDOT, P.; LAVAL, C. A nova razão do mundo: ensaio sobre a sociedade neoliberal. 1. ed. São Paulo: Boitempo, 2016.

HARVEY, D. O neoliberalismo: história e implicações. 5. ed. São Paulo: Edições Loyola, 2014.

HAYEK, F. V. O caminho da servidão. 6. ed. São Paulo: Instituto Ludwig von Mises Brasil, 2010.

HOBSBAWM, E. J. A era das revoluções: 1789-1848. 9. ed. Rio de Janeiro: Paz e Terra, 1996.

LASKI, H. J. O liberalismo europeu. 1. ed. São Paulo: Editora Mestre Jou, 1973.

LIBÂNEO, J. C.; OLIVEIRA, J. F.; TOSCHI, M. S. Educação escolar: políticas, estrutura e organização. São Paulo: Cortez, 2003.

MARX, K. Manuscritos econômico-filosóficos e outros textos escolhidos. 2. ed. São Paulo: Abril Cultural, 1978.

MERQUIOR, J. G. O liberalismo - antigo e moderno. Rio de Janeiro: Nova Fronteira, 1991. MORAES, R. C. Neoliberalismo: de onde vem, para onde vai? São Paulo: SENAC, 2001. 
LEMOS, A. G. de S.

NETTO, J. P.; BRAZ, M. Economia Política: uma introdução crítica. 8. ed. São Paulo: Cortez, 2012.

Adriane GuImarães de SiqueIRA LemOs: Doutoranda no Programa de Pós-Graduação em
Educação da Faculdade de Educação da Universidade Federal de Goiás. Mestra em
Educação pela Faculdade de Educação da Universidade Federal de Goiás. Especialista em
Psicologia dos Processos Educativos, pela Universidade Federal de Goiás; em Docência no
Ensino Superior, pela Faculdade Alfredo Nasser; em Psicopedagogia com ênfase no ensino
especial e educação inclusiva, pela Faculdade de Tecnologia Equipe Darwin - FTED.
Graduada em Pedagogia pela Universidade Federal de Goiás e complementação na área de
Português em Curso de Formação Pedagógica - PREFOP pela Universidade Estadual Vale
do Acaraú. Professora da Secretaria Estadual de Educação de Goiás (SEDUCGO).
Orcid: https://orcid.org/O000-0002-9041-1879
E-mail: adrianegsiqueira@hotmail.com

Este periódico utiliza a licença Creative Commons Attribution 3.0, para periódicos de acesso aberto (Open Archives Iniciative - OAI). 